\title{
Synthesis, characterization, and photocatalytic activity of MCM-41 and MCM-48 impregnated with $\mathrm{CeO}_{2}$ nanoparticles
}

\author{
Hamid Reza Pouretedal ${ }^{1 *}$ and Mina Ahmadi ${ }^{2}$
}

\begin{abstract}
MCM-41/CeO 2 and $\mathrm{MCM}-48 / \mathrm{CeO}_{2}$ were synthesized by direct and indirect methods in solvent media and by grinding method in a solvent-free media. The materials prepared by grinding method are characterized by X-ray diffraction, infrared spectrum analysis, and $\mathrm{N}_{2}$ adsorption and desorption. Surface areas and pore size of MCM-48 $/ \mathrm{CeO}_{2}$ were obtained with values of $680.9 \mathrm{~m}^{2} \cdot \mathrm{g}^{-1}$ and $1.64 \mathrm{~nm}$, respectively, by BET method. The results showed that $\mathrm{CeO}_{2}$ nanoparticles were introduced into MCM-41 and MCM-48, and there was formation of $\mathrm{CeO}_{2}$ crystallites as secondary phase in the extra framework of MCM-41 and MCM-48. MCM-41/CeO 2 and MCM-48/CeO $\mathrm{C}_{2}$ aterials are used as photocatalysts in degradation of Congo red as a dye pollutant. The $\mathrm{MCM}-41 / \mathrm{CeO}_{2}$ and $\mathrm{MCM}-48 / \mathrm{CeO}_{2}$ prepared by grinding method showed the higher photoreactivity with $97.6 \%$ and $93.1 \%$, respectively, of degradation of Congo red. The higher photoreactivity is due to the complete incorporation of cerium ions in mesoporous material of MCMs in a solvent-free media.
\end{abstract}

Keywords: Photocatalytic, MCM-41, MCM-48, $\mathrm{CeO}_{2}$, Congo red

\section{Background}

Ordered mesoporous materials such as MCM-41, MCM-48, and SBAs have been the subject of intensive research in the field of heterogeneous catalysis owing to their high surface area, uniform pores, and relatively high thermal stability [1]. These materials containing various transition metals are used as heterogeneous catalysts for many organic compound reactions [2,3]. Pure silica mesoporous material has only a few crystal defects and low reaction activity. Because of these disadvantages, researchers attempt to introduce some nanoparticles into this mesoporous material. The successful usages of the transition and rare earth metals in the catalysts are mainly the promoters; in oxides or in the microporous material, some attention have been paid to the combination of the transition and rare earth metals with the mesoporous materials in which the transition and rare earth metals are used as the active components of catalyst [2-4].

\footnotetext{
* Correspondence: HR_POURETEDAL@mut-es.ac.ir

${ }^{1}$ Faculty of Applied Chemistry, Malek-Ashtar University of Technology,

Shahin-Shahr 83145-115, Iran

Full list of author information is available at the end of the article
}

Cerium oxide is one of the most reactive rare earth metal oxides, which has been extensively studied and employed in various applications including fast ion conductors, oxygen storage capacitors, catalysts, UV blockers, polishing materials, and electrolytes for solid oxide fuel cells [5]. $\mathrm{CeO}_{2}$ or $\mathrm{CeO}_{2}$-based materials have also been found to be very important in environmental protection. In particular, supported $\mathrm{CeO}_{2}$ and $\mathrm{CeO}_{2}$-based mixed oxides are effective catalysts for the oxidation of different hydrocarbons and for the removal of organics from polluted water from different sources [6].

In this study, the impregnation synthesis of MCM-41/ $\mathrm{CeO}_{2}$ and $\mathrm{MCM}-48 / \mathrm{CeO}_{2}$ was done using direct and indirect solvothermal and grinding (without solvent) methods. The mesoporous materials of MCM-41 and MCM-48 were synthesized hydrothermally at ambient temperature conditions. A comparative study in structural properties of $\mathrm{MCM}-41 / \mathrm{CeO}_{2}$ and $\mathrm{MCM}-48 / \mathrm{CeO}_{2}$ materials was evaluated. The performance of these substrates toward the photocatalytic degradation of Congo red in aqueous solution was studied. 


\section{Methods}

\section{Synthesis of MCM-41 and MCM-48}

All of the materials purchased are of highest purity. All solutions were prepared with double distilled water. MCM41 was synthesized by dispersion of sodium silicate ( $2.5 \mathrm{~g}$ ) in deionized water $(18.24 \mathrm{ml})$ [7]. The surfactant cetyltrimethylammonium bromide (CTAB) was added after stirring the components. The reaction mixture was stirred for $45 \mathrm{~min}$ at room temperature. During the vigorous stirring, an adequate amount of $25 \%$ solution of tetramethylammonium hydroxide was added, and the $\mathrm{pH}$ was adjusted at 10 to 11 . The mixture was stirred at room temperature for $24 \mathrm{~h}$, then introduced into a Teflon-lined autoclave, and kept at a temperature of $100{ }^{\circ} \mathrm{C}$ for 3 days. The powder was recovered by filtration, was subsequently washed with acidic water-ethanol solution, and then dried in a vacuum oven. The obtained solid was calcined at $500{ }^{\circ} \mathrm{C}$ for $4 \mathrm{~h}$.

Sodium hydroxide and tetraethyl orthosilicate (TEOS) were added to the CTAB solution in the synthesis of MCM-48. The molar composition of the obtained gel is $1 \mathrm{M}$ TEOS:0.25 M Na $2 \mathrm{O}: 0.65 \mathrm{M}$ CTAB:0.62 $\mathrm{M} \mathrm{H}_{2} \mathrm{O}$ [8]. The solution was stirred for about $1 \mathrm{~h}$, then transferred into a polypropylene bottle, and heated up to $100{ }^{\circ} \mathrm{C}$ for 3 days. The product was filtered, washed with water, and dried in air at ambient temperature. The dried product was finally calcined at $550{ }^{\circ} \mathrm{C}$ for $6 \mathrm{~h}$.

\section{Synthesis of $\mathrm{MCM}-41 / \mathrm{CeO}_{2}$ and $\mathrm{MCM}-48 / \mathrm{CeO}_{2}$ by indirect method}

Some polyethylene glycol as dispersant agent was added to the solution of $\left(\mathrm{NH}_{4}\right)_{2} \mathrm{Ce}\left(\mathrm{NO}_{3}\right)_{6}(0.2134 \mathrm{~g})$, and then $0.1 \mathrm{~g}$ of synthesized MCM-41 and/or MCM-48 material was added into the cerium solution. After heating the solution till $40{ }^{\circ} \mathrm{C}$ under stirring and adjusting the $\mathrm{pH}$ to 7 to 8 , ammonium nitrate solution was quickly added, and then the mixed solution was thoroughly stirred for $30 \mathrm{~min}$. After aging for $12 \mathrm{~h}$, the colloid was filtered, washed, and dried in a vacuum oven at $60{ }^{\circ} \mathrm{C}$ for $10 \mathrm{~h}$. The synthesized sample was calcined at $600{ }^{\circ} \mathrm{C}$ for $5 \mathrm{~h}$ in air stream with a heating rate of $10{ }^{\circ} \mathrm{C} / \mathrm{min}$ [9]. Cooling it naturally with ambient temperature, $\mathrm{MCM}-41 / \mathrm{CeO}_{2}$ (40 wt.\%) and $\mathrm{MCM}-48 / \mathrm{CeO}_{2}$ (40 wt.\%) were gained.

\section{Synthesis of $\mathrm{MCM}-41 / \mathrm{CeO}_{2}$ and $\mathrm{MCM}-48 / \mathrm{CeO}_{2}$ by direct method}

MCM-41/ $\mathrm{CeO}_{2}$ and MCM-48/CeO 2 were prepared using a modified Stöber's synthesis at room temperature. The weight percent of $\mathrm{CeO}_{2}$ in prepared materials is $40 \%$. In a typical synthesis, $12.5 \mathrm{~g}$ of hexadecyltrimethylammonium bromide and the required amount $(0.2134 \mathrm{~g})$ of ammonium cerium nitrate are taken in a polypropylene bottle. Water and ethanol were added to the obtained mixture, which was stirred well until the dissolution of the metal precursor was completed. To this solution, $\mathrm{NH}_{3}$ was added followed by $1.8 \mathrm{ml}$ of TEOS. The precipitate obtained was filtered and washed with deionized water extensively. The solid was dried at $80{ }^{\circ} \mathrm{C}$ overnight in static air. The dried powder was ground finely and calcined in static air at $550{ }^{\circ} \mathrm{C}$ to remove the surfactant molecules for $6 \mathrm{~h}$ [10].

\section{Synthesis of $\mathrm{MCM}-41 / \mathrm{CeO}_{2}$ and $\mathrm{MCM}-48 / \mathrm{CeO}_{2}$ by grinding method}

In this method, 0.2134 $\mathrm{g}$ of $\left(\mathrm{NH}_{4}\right)_{2} \mathrm{Ce}\left(\mathrm{NO}_{3}\right)_{6}$ and $0.1 \mathrm{~g}$ of synthesized MCM-41 and/or MCM-48 were placed in a mortar and ground drastically at room temperature. The obtained solid was calcined at $550{ }^{\circ} \mathrm{C}$ in air for 3 to $4 \mathrm{~h}$ to remove the surfactant molecules [11]. $\mathrm{MCM}-41 / \mathrm{CeO}_{2}$ (40 wt.\%) and $\mathrm{MCM}-48 / \mathrm{CeO}_{2}$ (40 wt.\%) were obtained.

\section{Photocatalytic activity of prepared photocatalysts}

Photocatalytic degradation of Congo red (CR) was studied at $25{ }^{\circ} \mathrm{C}$ and $\mathrm{pH}=7$ to 8 in the presence of prepared catalysts. The degradation was carried out in a Pyrex photoreactor that has a high pressure mercury lamp of $70 \mathrm{~W}$ with maximum irradiation at a wavelength of $332 \mathrm{~nm}$. The degradation was performed at suitable time intervals at room temperature while the samples were stirred continuously. The photoreactor was filled with $25 \mathrm{ml}$ of $10 \mathrm{mg} / \mathrm{l}$ $\mathrm{CR}$ and $0.7 \mathrm{~g} / \mathrm{l}$ catalysts. The degradation efficiency (\%D) was calculated using initial concentration $\left(C_{\mathrm{o}}\right)$ and residual concentration $\left(C_{\mathrm{t}}\right)$ of $\mathrm{CR}$ by spectrophotometric method at $\lambda$ of $510 \mathrm{~nm}\left(\% \mathrm{D}=\left[\left(C_{\mathrm{o}}-C_{\mathrm{t}}\right) / C_{\mathrm{o}}\right] \times 100\right)$. The kinetic rate constant of degradation $\left(k_{\text {obs }}\right)$ was calculated using the model of Langmuir-Hinshelwood's kinetic expression (ln $\left.\left(C_{\mathrm{o}} / C_{\mathrm{t}}\right)=k_{\mathrm{obs}} t\right)[12]$.

\section{Results and discussion}

\section{Characterization of $\mathrm{MCM}-41 / \mathrm{CeO}_{2}$ and $\mathrm{MCM}-48 / \mathrm{CeO}_{2}$}

The characterization of MCM-41, MCM-48, $\mathrm{MCM}-41 / \mathrm{CeO}_{2}$, and $\mathrm{MCM}-48 / \mathrm{CeO}_{2}$ prepared by grinding method are performed using X-ray diffraction (XRD), Fourier transform infrared (FT-IR) spectroscopy, and Brunauer, Emmett, and Teller (BET) $\mathrm{N}_{2}$ adsorption-desorption isotherm. The XRD patterns of MCM-41 and $\mathrm{MCM}-41 / \mathrm{CeO}_{2}$ samples and MCM-48 and MCM-48/CeO 2 samples are shown, respectively, in Figures 1 and 2. The hexagonal and cubic ordered structured of MCM-41 and MCM-48, respectively, are confirmed by the XRD patterns [9].

In Figure 1a, in the small-angle XRD patterns of the prepared material MCM-41, an intense diffraction peak (100), together with an additional peak (110), and a very weak peak (200) were observed. It can be seen that peak (200) is not strong enough and also that the diffraction peaks move to the high angle, and the peaks become weaker when the $\mathrm{CeO}_{2}$ particles are doped into MCM-41. The increase of $\mathrm{CeO}_{2}$ particles in the framework of MCM-41 is due to reduction of the tunnel size of the substrate [9-11]. The XRD patterns of MCM-41 and MCM-41/CeO 2 (wide angle) are 


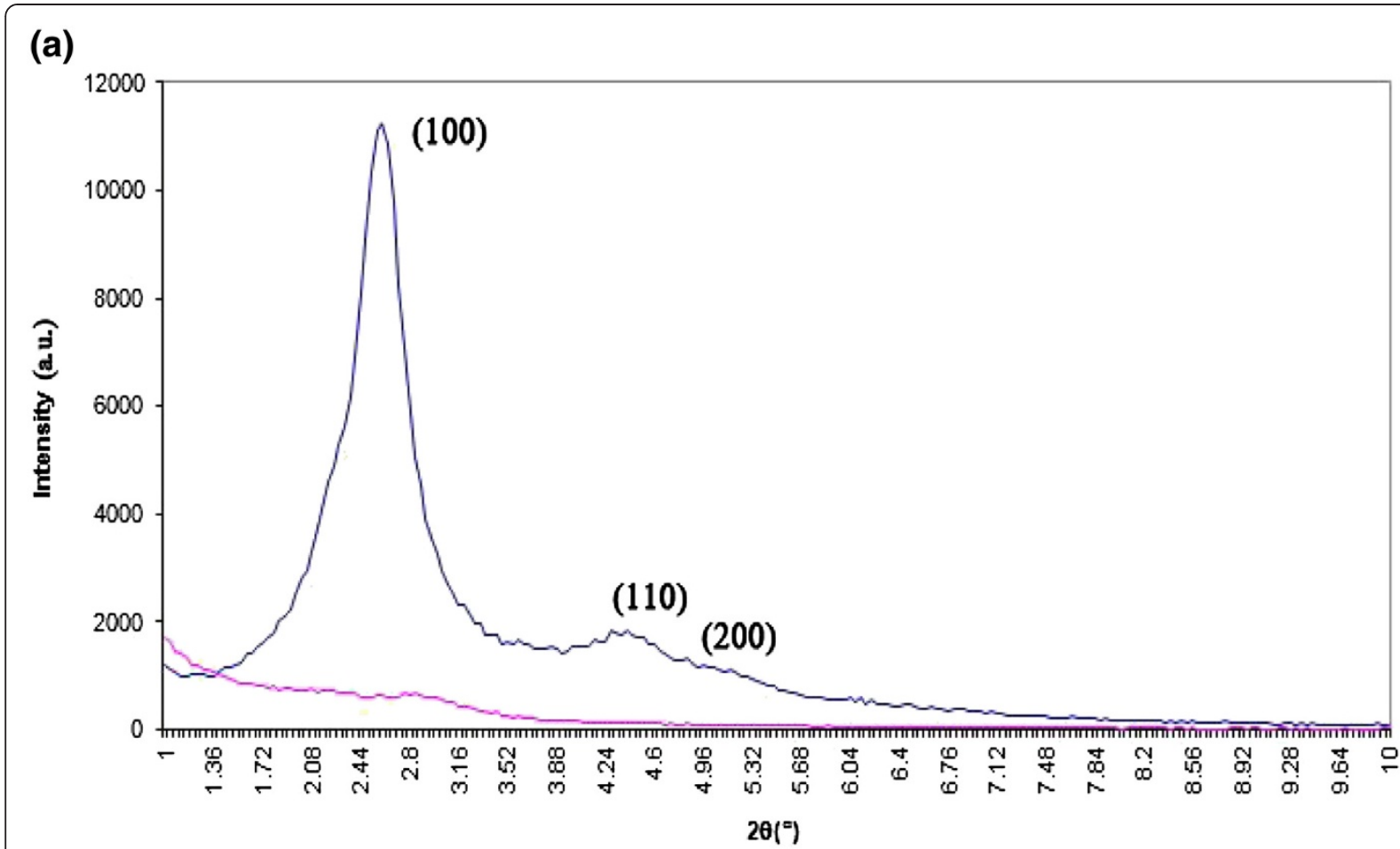

(b)

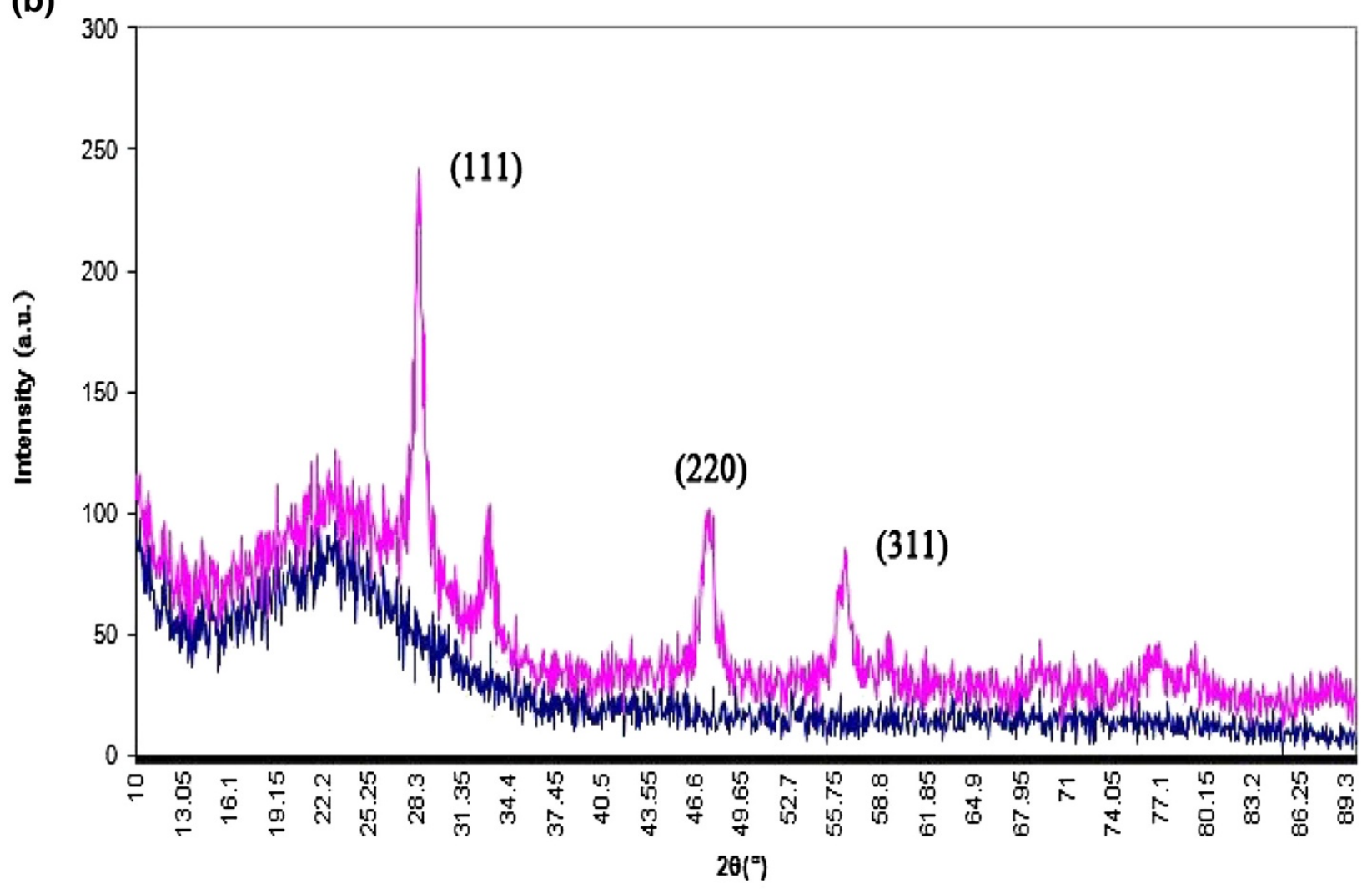

Figure 1 Small-angle (a) and wide-angle (b) XRD patterns of samples (1) MCM-41 and (2) $\mathrm{MCM}-41 / \mathrm{CeO}_{2}$. 


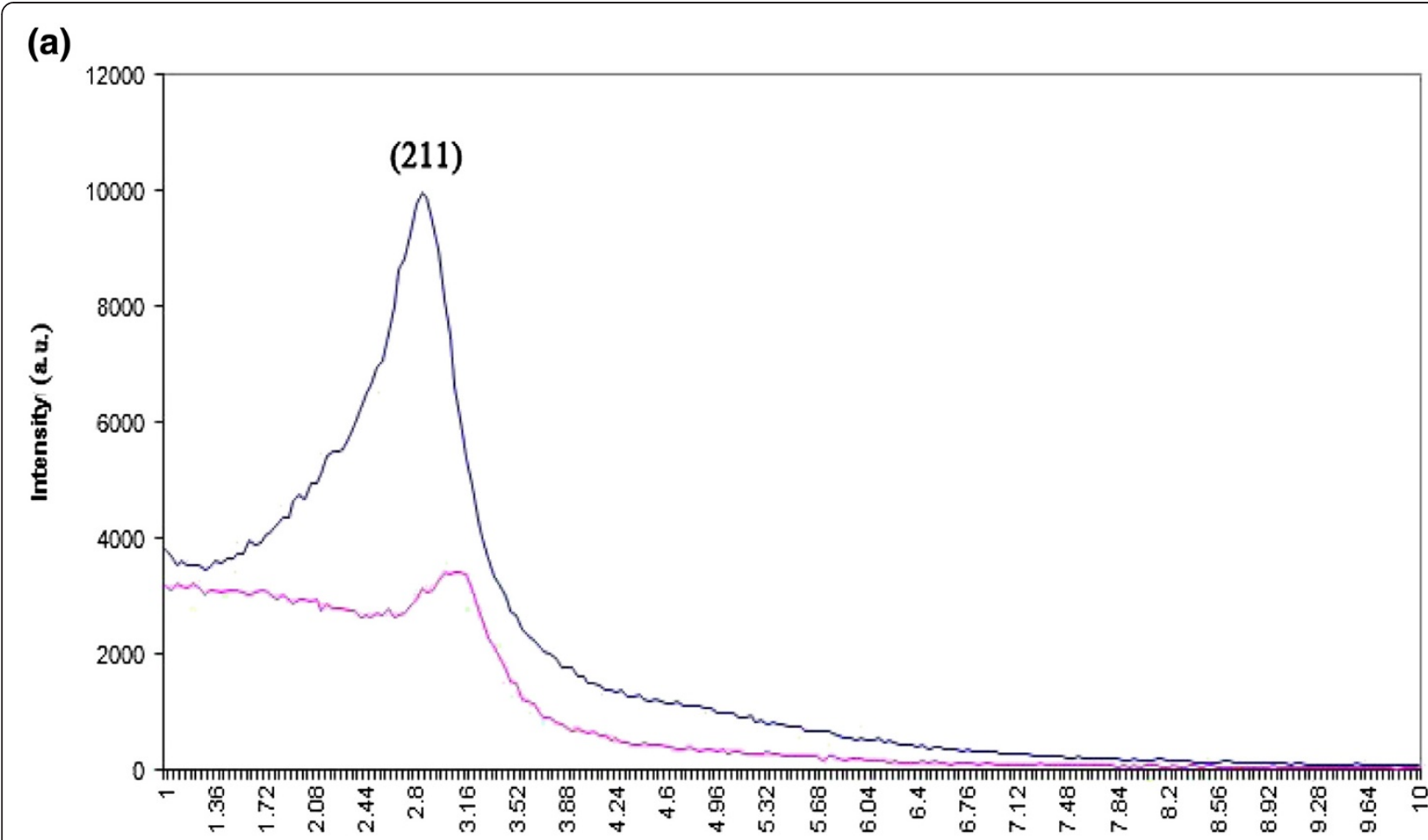

$20\left(^{\circ}\right)$

(b)

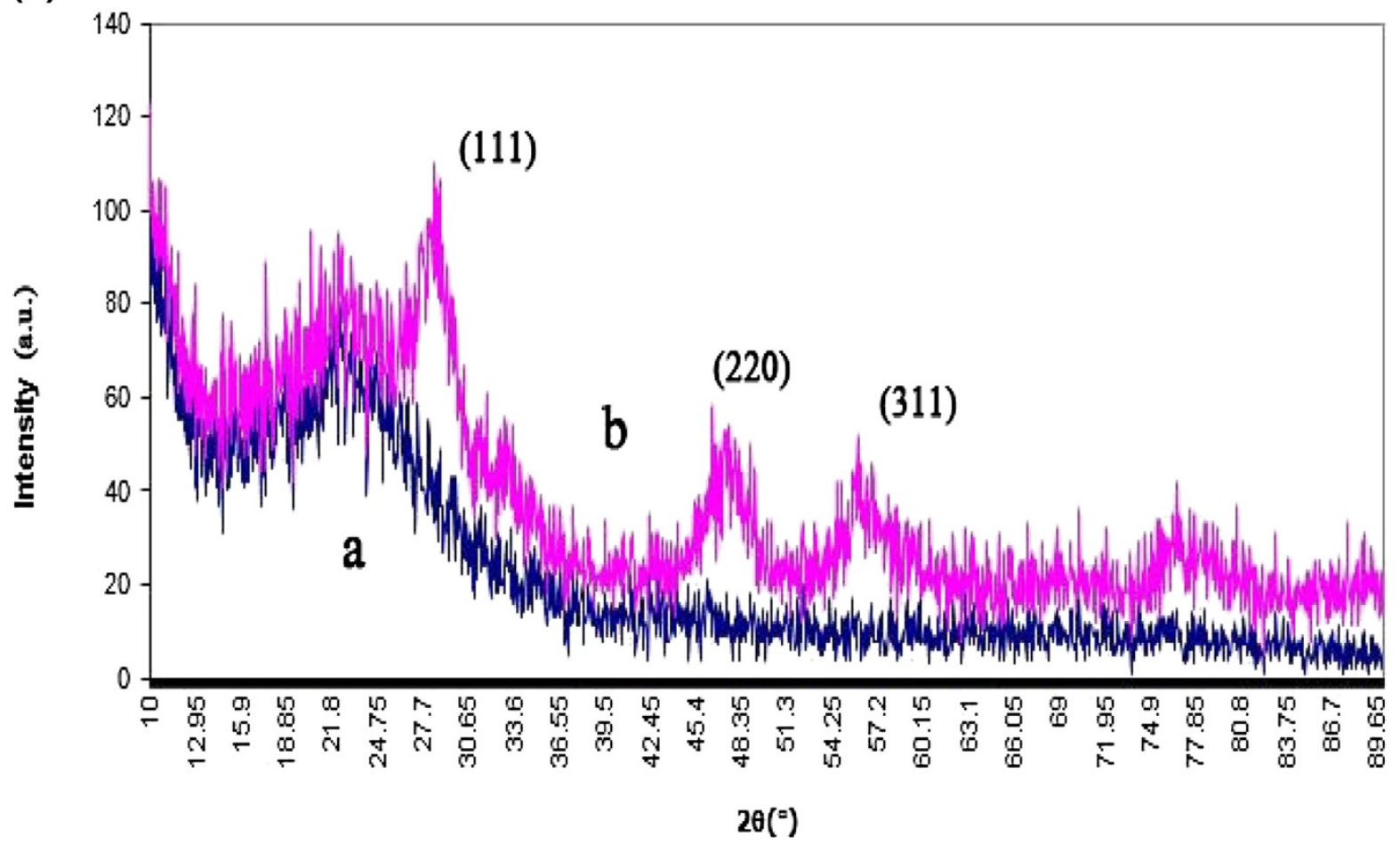

Figure 2 Small-angle (a) and wide-angle (b) XRD patterns of samples (1) MCM-48 and (2) $\mathrm{MCM}-48 / \mathrm{CeO}_{2}$. 
shown in Figure 1b. The main substance of MCM-41 is amorphous silica as evident in one diffusion peak observed in the pattern of MCM-41. However, the peak of amorphous silica became weaker, and the peaks of $\mathrm{CeO}_{2}$ appeared when the $\mathrm{CeO}_{2}$ nanoparticles are introduced into MCM-41 [9]. The peaks with $2 \theta$ values of $28.3,33.2,47.5$ and 56.4 correspond to the (111), (200), (220), and (311) planes [13].

In the small-angle XRD patterns of MCM-48, the most intense diffraction peak (211) appears at $2 \theta=2.9^{\circ}$ (Figure 2a), while low intense diffraction peaks are seen at $2 \theta=3^{\circ}$ to $6^{\circ}$. With cerium doping and a gradual loss of long-range ordering of MCM-48, the intensity of the diffraction peak of $\mathrm{MCM}-48 / \mathrm{CeO}_{2}$ decreases at a small angle. The diffraction peaks of $\mathrm{CeO}_{2}$ in the wide-angle XRD pattern have appeared obviously which show the content of $\mathrm{CeO}_{2}$ in the channel (or in the extra framework) of the sample [14].

The FT-IR spectra of MCM-41 and MCM-41/CeO are shown in Figure 3. In the spectra of MCM-41, the stretching vibrating absorption peaks of the $\mathrm{O}-\mathrm{H}$ band in the surfaced hydroxyl and in the planar water is seen at $3,440 \mathrm{~cm}^{-1}$. The symmetry and asymmetry flexural vibrating peaks of $\mathrm{Si}-\mathrm{O}-\mathrm{Si}$ at $1,080,812$, and $464 \mathrm{~cm}^{-1}$, respectively, are related to the framework of silicon [9]. As seen, there are some differences of the intensities of the peaks in the FT-IR spectra of MCM-41 and MCM-41/ $\mathrm{CeO}_{2}$, which resulted from the doping of $\mathrm{CeO}_{2}$. A strong absorption peak at $1,632 \mathrm{~cm}^{-1}$ is observed in the spectra of $\mathrm{MCM}-41 / \mathrm{CeO}_{2}$, and it indicates the formation of CeO-Ce [9].

Figure 4 shows the FT-IR absorption spectra of the MCM-48 and MCM-48/CeO 2 samples. The absorption bands of asymmetric vibration of $\mathrm{Si}-\mathrm{O}-\mathrm{Si}$ of the silica framework appear at 1,200 and $1,080 \mathrm{~cm}^{-1}$. The stretching vibration peak of silica is at $815 \mathrm{~cm}^{-1}$. The vibration band at $1,080 \mathrm{~cm}^{-1}$ are shifted 4 to $9 \mathrm{~cm}^{-1}$ for the $\mathrm{MCM}-48 / \mathrm{CeO}_{2}$ sample compared with the spectrum

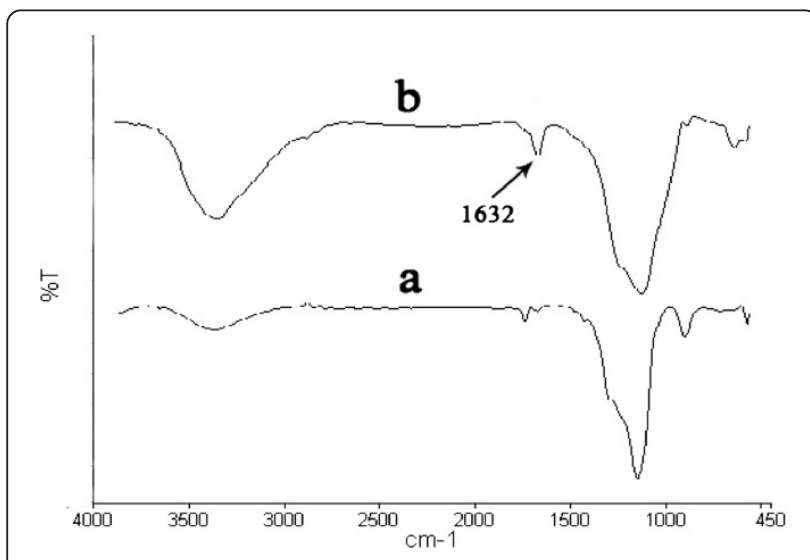

Figure 3 FT-IR spectra of (a) MCM-41 and (b) $M C M-41 / \mathrm{CeO}_{2}$.

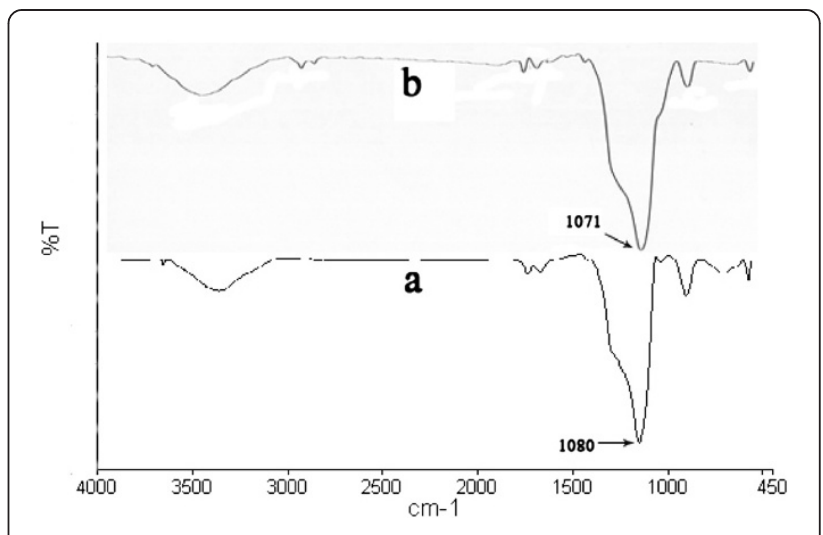

Figure 4 FT-IR spectra of (a) MCM-48 and (b) $\mathrm{MCM}-48 / \mathrm{CeO}_{2}$.

of MCM-48. This shift is due to the incorporation of Ce into the framework of MCM-48 [14].

The $\mathrm{N}_{2}$ adsorption and desorption isotherms of the MCM-48/CeO 2 sample is shown in Figure 5, and the corresponding pore size distribution curve is shown in Figure 6. It is shown that these isotherms have the typical characteristics of the mesoporous material isotherm and are of the type IV according to the IUPAC classification [14]. The BET surface areas, average pore size calculated by the $\mathrm{BJH}$ model, and the pore volume of MCM-48 [14] and $\mathrm{MCM}-48 / \mathrm{CeO}_{2}$ samples are presented in Table 1.

\section{Photocatalytic degradation of Congo red}

The control experiment indicates that CR was not degraded completely when irradiated with UV in the absence of a catalyst; only $24.7 \%$ was degraded after $120 \mathrm{~min}$. The primary factor of photocatalytic degradation is the adsorption of $\mathrm{CR}$ onto the catalyst surface via the interaction of surface hydroxyl groups, particularly onto high-surface area support, i.e., MCM-41 and MCM-48 [15]. In other words, the adsorption of anionic dye on oxide surface is favored, leading to an increase of the dye concentration on the surface and the facilitation of photocatalytic degradation of the dye being investigated $[16,17]$. The presence of transition metal cations such as cerium doped on the mesoporous materials, such as MCM-41 and MCM-48, may prevent the recombination between the photogenerated holes and electrons or elongate the time of charge separation because it acts as an electron acceptor center $[18,19]$. One can assumed that the hydroxyl groups on the surface of prepared catalysts act as an electron donor for photogenerated $\mathrm{H}^{+}$, forming active hydroxyl radicals $\left(\mathrm{OH}^{\cdot+}\right)$ which attack the $\mathrm{CR}$.

Table 2 shows the performances of $\mathrm{MCM}-41 / \mathrm{CeO}_{2}$ and $\mathrm{MCM}-48 / \mathrm{CeO}_{2}$ (prepared by different methods) and nanoparticles of $\mathrm{CeO}_{2}$ as photocatalysts for the photocatalytic degradation of $\mathrm{CR}$ in $120 \mathrm{~min}$. The $k_{\mathrm{obs}}$ values are also 


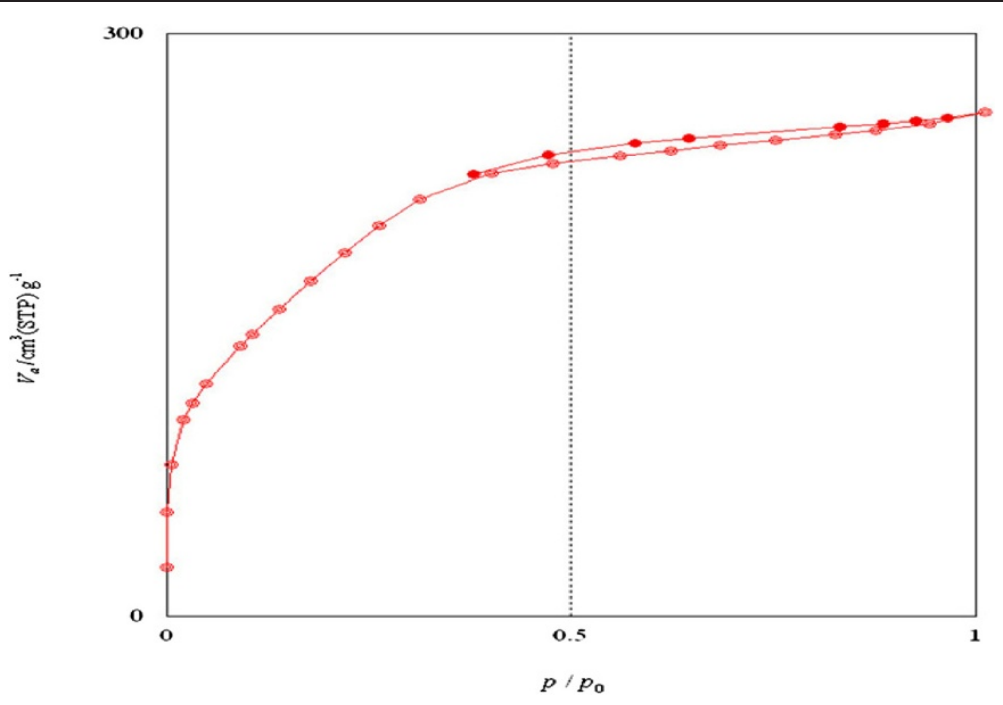

Figure 5 Nitrogen adsorption and desorption isotherms of $\mathrm{MCM}-48 / \mathrm{CeO}_{2}$.

collected in Table 2. Among the prepared catalysts, the mesoporous $\mathrm{MCM}-41 / \mathrm{CeO}_{2}$ and $\mathrm{MCM}-48 / \mathrm{CeO}_{2}$ that were synthesized by grinding method show the most photocatalytic activity with $97.6 \%$ and $91.3 \%$ photodegradation of $\mathrm{CR}$, respectively. Apparently, the most cerium ions are doped in mesoporous materials by grinding method, and the weight percentage of $\mathrm{CeO}_{2}$ in $\mathrm{MCM} / \mathrm{CeO}_{2}$ is near $40 \%$ which is in accordance to what was mentioned in the 'Methods' section. However, a lot of cerium ions have been lost in the preparation of $\mathrm{MCM} / \mathrm{CeO}_{2}$ by direct and indirect methods in a solvent medium.
The amount of CR degraded on the surface of the different catalysts showed the order of sequence: $\mathrm{MCM}-41 / \mathrm{CeO}_{2}>$ MCM-48/ $\mathrm{CeO}_{2}>\mathrm{CeO}_{2}$, which can be directly related to the surface area that is available for adsorption. As for $\mathrm{CeO}_{2}$ nanoparticles, they show $51.9 \%$ of degradation. However, good photodegradation is obtained over the $\mathrm{MCMs} / \mathrm{CeO}_{2}$ catalyst. The enhanced photocatalytic activity over the composite $\mathrm{MCMs} / \mathrm{CeO}_{2}$ is reflecting the beneficial adsorption properties of MCM-41 and MCM-48. Thus, it is clear that the presence of cerium in $\mathrm{MCM}-41 / \mathrm{CeO}_{2}$ and MCM-48/ $\mathrm{CeO}_{2}$ plays a role in the catalytic reaction, that is to say, the

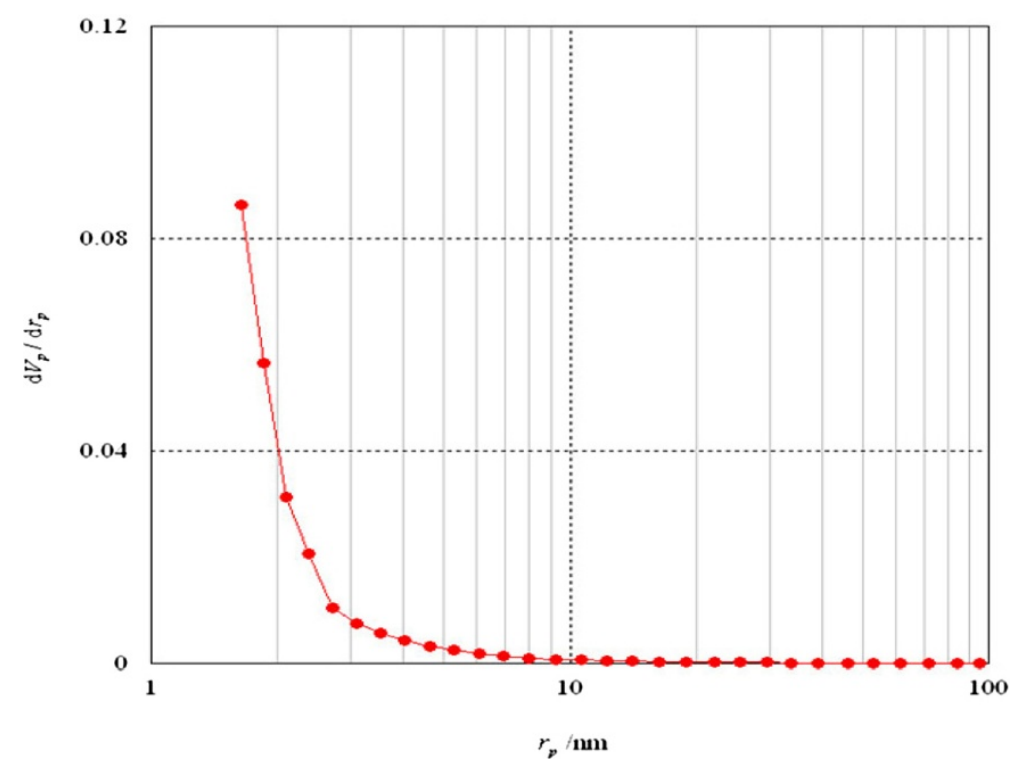

Figure 6 Pore size distribution curves of $\mathrm{MCM}-48 / \mathrm{CeO}_{2}$. 
Table 1 Textural properties of MCM-48 and MCM-48/CeO samples

\begin{tabular}{lccc}
\hline Sample & $\begin{array}{c}\text { Surface area } \\
\left(\mathbf{m}^{\mathbf{2}} \cdot \mathbf{g}^{-\mathbf{1}}\right)\end{array}$ & $\begin{array}{c}\text { Pore volume } \\
\left(\mathbf{c m}^{\mathbf{3}} \cdot \mathbf{g}^{-\mathbf{1}}\right)\end{array}$ & $\begin{array}{c}\text { Pore size } \\
(\mathbf{n m})\end{array}$ \\
\hline $\mathrm{MCM}-48$ & 895.0 & 0.850 & 2.23 \\
$\mathrm{MCM}-48 /$ & 680.9 & 0.398 & 1.64 \\
$\mathrm{CeO}_{2}$ & & & \\
\hline
\end{tabular}

Ce ions that dispersed highly in $\mathrm{MCM} / \mathrm{CeO}_{2}$ are the active sites. The enhancements of $\mathrm{CR}$ degradation may be due to the high dispersion of $\mathrm{CeO}_{2}$ in the amorphous wall of MCM-41 and MCM-48 and the increase of the bandgap between the conduction band and valance band of $\mathrm{CeO}_{2}$ in MCMs. In addition, due to the wide bandgap of MCM-41/ $\mathrm{CeO}_{2}$ and $\mathrm{MCM}-48 / \mathrm{CeO}_{2}$, the lifetime of photogenerated holes and electrons of the $\mathrm{MCMs} / \mathrm{CeO}_{2}$ is longer than that of $\mathrm{CeO}_{2}$ nanoparticles [20-22].

The higher activity of $\mathrm{MCM}-41 / \mathrm{CeO}_{2}$ may be due to the hexagonal ordered structured compared to MCM-48 with cubic ordered structured [21,22]. The hexagonal ordered structured of MCM-41 due to the higher dispersion of cerium on this sample.

\section{Conclusions}

The grinding method can be used to prepare cerium-doped MCM-41 and MCM-48 mesoporous materials. Using this method, certain cerium cations can be incorporated into the framework of MCM-41 and MCM-48. After $\mathrm{CeO}_{2}$ particles are being doped into substrates of MCM-41 and MCM-48, the surface area of the material was reduced, and the pore volume also decreased. The prepared MCM-41/ $\mathrm{CeO}_{2}$ and $\mathrm{MCM}-48 / \mathrm{CeO}_{2}$ show the photoreactivity in $\mathrm{CR}$ degradation. The hexagonal structure of MCM-41 has a larger surface area and has active sites. Also, there are $\mathrm{CeO}_{2}$ nanoparticles in the secondary phase in the extra framework of mesoporous materials. Thus, the $\mathrm{MCM}-41 / \mathrm{CeO}_{2}$ catalyst exhibits the higher reactivity in comparison with $\mathrm{MCM}-48 / \mathrm{CeO}_{2}$.

Table 2 CR degradation in $120 \mathrm{~min}$ and $\boldsymbol{k}_{\text {obs }}$ of photocatalytic process over $\mathrm{CeO}_{2}, \mathrm{MCM}-41 / \mathrm{CeO}_{2}$, and $\mathrm{MCM}-48 / \mathrm{CeO}_{2}$

\begin{tabular}{lcc}
\hline Catalysts & \% & $\boldsymbol{k}_{\text {obs }} \times \mathbf{1 0}^{-\mathbf{3}}\left(\mathbf{m i n}^{\mathbf{- 1}}\right)$ \\
\hline Without photocatalyst & 24.7 & 1.9 \\
$\mathrm{CeO}_{2}$ & 51.9 & 6.0 \\
$\mathrm{MCM}-41 / \mathrm{CeO}_{2}$, direct method & 44.2 & 5.0 \\
$\mathrm{MCM}-48 / \mathrm{CeO}_{2}$, direct method & 37.6 & 3.7 \\
$\mathrm{MCM}-41 / \mathrm{CeO}_{2}$, indirect method & 52.7 & 6.0 \\
$\mathrm{MCM}-48 / \mathrm{CeO}_{2}$, indirect method & 46.7 & 5.4 \\
$\mathrm{MCM}-41 / \mathrm{CeO}_{2}$, grinding method & 97.6 & 36.0 \\
$\mathrm{MCM}-48 / \mathrm{CeO}_{2}$, grinding method & 91.3 & 22.7 \\
\hline
\end{tabular}

\section{Competing interests}

The authors declare that they have no competing interest.

\section{Acknowledgments}

The authors are grateful to the Malek-Ashtar University of Technology and Islamic Azad University, Shahreza Branch for the financial support of this work.

\section{Author details}

${ }^{1}$ Faculty of Applied Chemistry, Malek-Ashtar University of Technology, Shahin-Shahr 83145-115, Iran. ${ }^{2}$ Department of Chemistry, Islamic Azad University, Shahreza Branch, Shahreza, Iran.

\section{Authors' contribution}

Both authors participated in the experiments, read and approved the final manuscript.

\section{Authors' information}

HRP is an associate professor of Chemistry, and MA is an M.Sc. student of Chemistry.

Received: 22 April 2012 Accepted: 22 June 2012

Published: 22 June 2012

\section{References}

1. Kresge, C.T., Lenowicz, M.E, Roth, WJ, Vartuli, J.C, Beck, J.S: Ordered mesoporous molecular sieves synthesized by a liquid-crystal template mechanism. Nature 359, 710-712 (1992)

2. Kawabata, T, Ohishi, Y, Itsuki, S, Fujisaki, N, Shishido, T, Takaki, K, Zhang, Q, Wang, Y, Takehira, K I Iron-containing MCM-41 catalysts for Baeyer-Villiger oxidation of ketones using molecular oxygen and benzaldehyde. J. Mol. Catal. A 236, 99-106 (2005)

3. Koo, DH, Kim, GM, Chang, S: $\mathrm{WO}_{3}$ nanoparticles on MCM-48 as a highly selective and versatile heterogeneous catalyst for the oxidation of olefins, sulfides, and cyclic ketones. Org. Lett. 7, 5015-5018 (2005)

4. Moller, K, Bein, T: Inclusion chemistry in periodic mesoporous hosts. Chem. Mater. 10, 2950-2963 (1998)

5. Wang, Z, Feng, X: Polyhedral shapes of $\mathrm{CeO}_{2}$ nanoparticles. J. Phys. Chem. B 107, 13563-13566 (2003)

6. Monteiro, R.S., Dieguez, LC., Schmal, M: The role of Pd precursors in the oxidation of carbon monoxide over $\mathrm{Pd} / \mathrm{Al}_{2} \mathrm{O}_{3}$ and $\mathrm{Pd} / \mathrm{CeO}_{2} / \mathrm{Al}_{2} \mathrm{O}_{3}$ catalysts. Catal. Today 65 , 77-89 (2001)

7. Nazari, K, Shokrollahzadeh, S, Mahmoudi, A, Mesbahi, F, Seyed Matin, N, Moosavi-Movahedi, AA: Iron(III)protoporphyrin/MCM41 catalyst as a peroxidase enzyme model: preparation and typical test reactions. J. Mol. Catal. A. Chem 239, 1-9 (2005)

8. Kumar, D., Schumacher, K, Hohenesche, C.D, Grün, M, Unger, KK: MCM-41, MCM-48 and related mesoporous adsorbents: their synthesis and characterization. Coll. Surf. A Physicochem. Eng. Aspects 187-188, 109-116 (2001)

9. Song, X, Qu, P, Jiang, N, Yang, H, Qiu, G: Synthesis and characterization of MCM-41 materials assembled with $\mathrm{CeO}_{2}$ nanoparticles. Coll. Surf. A Physicochem. Eng. Aspects 313-314, 193-196 (2008)

10. Subramanian, H, Nettleton, EG, Budhi, S, Koodali, RT: Baeyer-Villiger oxidation of cyclic ketones using Fe containing MCM-48 cubic mesoporous materials. J. Mol. Catal. A. Chem. 330, 66-72 (2010)

11. Li, Y, Yan, B: Functionalized mesoporous SBA-15 with CeF3: Eu3+ nanoparticle by three different methods: synthesis, characterization, and photoluminescence. Nanoscal. Res. Lett. 5, 701-708 (2010)

12. Al-Ekabi, $\mathrm{H}$, Serpone, N: Kinetic studies in heterogeneous photocatalysis. J. Phys. Chem. 92, 5726-5731 (1988)

13. Pouretedal, $\mathrm{HR}$, Kadkhodaie, A: Synthetic $\mathrm{CeO}_{2}$ nanoparticle catalysis of methylene blue photodegradation: kinetics and mechanism. Chin. J. Catal. 31, 1328-1334 (2010)

14. Wangcheng, Z, Guanzhong, L, Yanlong, G, Yun, G, Yanging, W, Yansong, W, Zhigang, Z, Xiaohui, L: Synthesis of cerium-doped MCM-48 molecular sieves and its catalytic performance for selective oxidation of cyclohexane. J. Rare Earths 26, 515-522 (2008)

15. Wang, $S, L i, H:$ Structure directed reversible adsorption of organic dye on mesoporous silica in aqueous solution. Micropor. Mesopor. Mater. 97, $21-26$ (2004)

16. $\mathrm{Fu}, \mathrm{P}, \mathrm{Luan}, \mathrm{Y}, \mathrm{Dai}, \mathrm{X}$ : Preparation of activated carbon fibers supported $\mathrm{TiO}_{2}$ photocatalyst and evaluation of its photocatalytic reactivity. J. Mol. Catal. A $221,81-88$ (2004) 
17. El-Sheikh, AH, Newman, AP, Al-Daffaee, H, Phull, S, Cresswell, N, York, S: Deposition of anatase on the surface of activated carbon. Surf. Coat. Thecnol. 187, 284-292 (2004)

18. Mohamed, M.M., Al-Esaimi, M.M.: Characterization, adsorption and photocatalytic activity of vanadium-doped $\mathrm{TiO}_{2}$ and sulfated $\mathrm{TiO}_{2}$ (rutile) catalysts: degradation of methylene blue dye. J. Mol. Catal. A. 255, 5361-5367 (2006)

19. Chu, W, Hu, J, Xie, Z, Chen, Q: Design and elaboration of new solid acids for the synthesis of butylacetate. Catal. Today 90, 349-353 (2004)

20. Ji, P, Zhang, J, Chen, F, Anpo, M: Ordered mesoporous $\mathrm{CeO}_{2}$ synthesized by nanocasting from cubic la3d mesoporous MCM-48 silica: formation, characterization and photocatalytic activity. J. Phys. Chem. C 112, 17809-17813 (2008)

21. Hadjiivanov, K, Tsoncheva, T, Dimitrov, M, Minchev, C, Knözinger, H: Characterization of Cu/MCM-41 and Cu/MCM-48 mesoporous catalysts by FTIR spectroscopy of adsorbed CO. Appl. Catal. A 241, 331-340 (2003)

22. Sakthivel, A, Dapurkar, SE, Selvam, P: Mesoporous (Cr)MCM-41 and (Cr)MCM-48 molecular sieves: promising heterogeneous catalysts for liquid phase oxidation reactions. Catal. Lett. 9, 155-158 (2001)

doi:10.1186/2228-5326-2-10

Cite this article as: Pouretedal and Ahmadi: Synthesis, characterization, and photocatalytic activity of MCM-41 and MCM-48 impregnated with $\mathrm{CeO}_{2}$ nanoparticles. International Nano Letters 2012 2:10.

\section{Submit your next manuscript to BioMed Central and take full advantage of:}

- Convenient online submission

- Thorough peer review

- No space constraints or color figure charges

- Immediate publication on acceptance

- Inclusion in PubMed, CAS, Scopus and Google Scholar

- Research which is freely available for redistribution 